\title{
Design, synthesis, bioactivity, and DFT calculation of 2-thiazolyl- hydrazone derivatives as influenza neuraminidase inhibitors
}

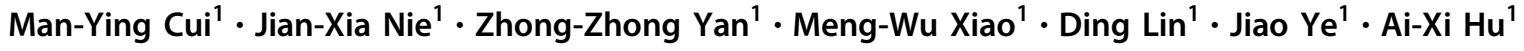

Received: 21 January 2019 / Accepted: 3 April 2019 / Published online: 30 April 2019

(c) Springer Science+Business Media, LLC, part of Springer Nature 2019

\begin{abstract}
Three series of thiazolylhydrazone derivatives were designed, synthesized, and evaluated for their neuraminidase (NA) inhibitory activity against influenza virus H1N1 in vitro. Compounds $\mathbf{1}$ and $\mathbf{2}$ were synthesized via the one-pot reaction and compound $\mathbf{3}$ was synthesized in two steps. Pharmacological results showed that the majority of the target compounds $\mathbf{1}, \mathbf{2}$, and $\mathbf{3}$ exhibited moderate-to-good influenza NA inhibitory activity. The NA inhibitory activity of the most active compound $\mathbf{2 g}\left(\mathrm{IC}_{50}=7.12\right.$ $\mu \mathrm{g} / \mathrm{ml}$ ) is better than that of the lead compound A. Molecular docking was performed to study the possible interactions between compound $\mathbf{2 g}$ and the active site of NA. On the basis of biological results, a preliminary structure-activity relationship (SAR) was derived and discussed. Moreover, density functional theory (DFT) calculation was also performed to explain why the thiazolylhydrazone skeleton has NA inhibitory activity, especially compound $\mathbf{2 g}$ with the most potent inhibitory activity.
\end{abstract}

Keywords Thiazolylhydrazones $\cdot$ Neuraminidase (NA) inhibitors $\cdot$ Molecular docking $\cdot$ DFT calculation

\section{Introduction}

Influenza commonly known as an infectious epidemic is a major cause for health concern and economic costs. According to statistics from WHO, seasonal influenza can cause 2-5 million infections and 250,000-500,000 deaths each year worldwide (Krammer et al. 2015; Dawood et al. 2012). Despite the fact that flu vaccine is effective to prevent influenza virus infection, it still needs updating as the influenza virus mutates annually and flu vaccine cannot treat large-scale influenza outbreaks (Ellebedy et al. 2009). However, it was reported that there are two main glycoproteins-hemagglutinin (HA) and neuraminidase (NA) on the surface of virus, which are responsible for the invasion of viruses and the release of offspring virus, respectively

Supplementary information The online version of this article (https:// doi.org/10.1007/s00044-019-02343-3) contains supplementary material, which is available to authorized users.

$\triangle$ Jiao Ye

yejiao@hnu.edu.cn

$\triangle \mathrm{Ai}-\mathrm{Xi} \mathrm{Hu}$

axhu@hnu.edu.cn

1 College of Chemistry and Chemical Engineering, Hunan University, 410082 Changsha, China

(Colman et al. 2012; Chavas et al. 2010). Moreover, further study indicated that over ten amino acid residues of neuraminidase's active site are highly conserved (Feng et al. 2012; Lou et al. 2014). Hence, compared with other targets, $\mathrm{NA}$ is an attractive target for anti-influenza research.

Currently, Zanamivir and Oseltamivir are two effective NA inhibitors that were approved in many countries (Baz et al. 2007; Ison 2011). Among them, Oseltamivir is the first-line drug for controlling pandemic influenza (Hatakeyama et al. 2007). However, more and more influenza virus strains are resistant to it, such as the seasonal H1N1 viruses and avian H5N1 strains (Takano et al. 2013). Zanamivir is rarely used because of their low bioavailability and rapid elimination analysis (MIST Study Group 1998). Thus, it is urgent to develop new and potential antiviral drugs to fight against human influenza pandemic.<smiles>CC(=O)N[C@H]1[C@H](NC(=N)N)C=C(C(=O)O)O[C@H]1[C@H](O)[C@H](O)CO</smiles>

Zanamivir<smiles>CCC(CC)OC1C=C(C(=O)Cl)C[C@H](N)[C@H]1NC(C)=O</smiles>

Oseltamivir 
In our previous studies, we found that compounds containing the hydrazone fragment always showed good NA inhibitory activity such as $(E)-2-((2-(4-($ tert-butyl)-5-(1H1,2,4-triazol-1-yl)thiazol-2-yl)hydrazono)methyl)-4,6-dinitrophenol hydrobromide (A, Fang et al. 2016) and 3-((4-(tbutyl)-2-(2-benzylidenehydrazinyl) thiazol-5-yl) methyl) quinolin-2(1H)-ones (B, Yuan et al. 2017). Moreover, in 2011, (Liu et al. 2011) found that the series of 2-(2-aminothiazol-4-yl) acetic acid derivatives showed good NA inhibitory activity, and the $\mathrm{IC}_{50}$ value of the most potent compound $\mathbf{C}$ was $1.28 \mu \mathrm{g} / \mathrm{ml}$ (Liu et al. 2011). In order to find more potent NA inhibitors, we kept the thiazolylhydrazone group of compound $\mathbf{A}$ or $\mathbf{B}$ and introduced ethyl acetate at the 4-position of the thiazole ring to design compound 1. However, compared with the lead compounds $\mathbf{A}$ and $\mathbf{B}$, the activity of compound $\mathbf{1}$ is not improved. So we introduced the methyl at the 4-position and acetyl at the 5-position of the thiazole ring to design compound 2. Fortunately, we found that compound $\mathbf{2}$ showed better activity than the lead compounds $\mathbf{A}$ and $\mathbf{B}$. Meanwhile, to make sure if acetophenone thiazolylhydrazone can affect the activity against NA, we designed a series of acetophenone thiazolylhydrazone derivatives 3 (Fig. 1). Compounds 1 and 2 were synthesized via a one-pot reaction, while compound $\mathbf{3}$ was synthesized in two steps. To further discuss the interaction of target compounds with NA, density functional theoretical (DFT) calculation and Ledock were carried out. The results show an obvious NA inhibitory activity regularity and excellent molecular docking effect.

\section{Results and discussion}

\section{Chemistry}

Compounds 1 and $\mathbf{2}$ were synthesized via a one-pot reaction from substituted benzaldehyde derivative $\mathbf{4}$, thiosemicarbazide, $\alpha$-haloketone $\mathbf{5}$, and catalytic sodium acetate refluxing in ethanol (Scheme 1). Compared with 3-bromineacetylacetone, the reaction selectivity of ethyl 4chloroacetoacetate was so poor that the yield of compound $1(41.8-70.0 \%)$ was lower than that of compound 2 (52.4-92.1\%). Instead of the one-pot reaction, compound $\mathbf{3}$ was easily synthesized in a two-step process with better yields. As a first step, the condensation of acetophenone derivative 6 and thiosemicarbazide was typically carried out in ethanol with acetic acid as the catalyst to produce thiosemicarbazone 7. As a second step, thiosemicarbazone 7 was cyclized with 3-bromineacetylacetone in ethanol to obtain compound 3. All the target compounds were characterized by nuclear magnetic resonance (NMR) spectroscopy and mass spectrometry (MS).

\section{In vitro inhibitory activities on NA}

The 32 target compounds were evaluated for the NA inhibitory activity against influenza virus neuraminidase (H1N1) in vitro using Oseltamivir as positive control. The preliminary biological results of three series of thiazolylhydrazone derivatives (Tables 1-3) show that many compounds displayed moderate-to-good inhibitory activity against NA.

As shown in Table 1, the activities of compound $\mathbf{1}$ were generally lower than the lead compounds $\mathbf{A}$ and $\mathbf{B}$. The most active one is compound $1 \mathrm{c}(\mathrm{R}=4-\mathrm{OH})$ with an $\mathrm{IC}_{50}$ value of $17.92 \pm 1.60 \mu \mathrm{g} / \mathrm{ml}$. To find out the reason why the activity is so poor, compound $\mathbf{C}$ was synthesized and evaluated for its NA inhibitory activity for activity control. However, unlike the reported activity result in the literature (Liu et al. 2011), compound C exhibited no inhibitory activity against NA. So we designed the target compound $\mathbf{2}$ for activity comparison. As a result, the ethyl acetate substituent at 4-position of the thiazole ring cannot enhance the activity.

Activity results (Table 2) suggest that all the compounds, including compound 2 display over 50\% inhibition rates at the test concentration of $40 \mu \mathrm{g} / \mathrm{mL}$. Moreover, there are two compounds $\mathbf{2} \mathbf{g}$ and $\mathbf{2} \mathbf{j}$ with inhibition rates of over $90 \%$. With further testing for $\mathrm{IC}_{50}$ values, compound $\mathbf{2}$ shows the $\mathrm{IC}_{50}$ values ranging from 7.12 to $34.31 \mu \mathrm{g} / \mathrm{ml}$. Especially, the most potent compound $\mathbf{2} \mathbf{g}$ shows the $\mathrm{IC}_{50}$ value of $7.12 \mu \mathrm{g} / \mathrm{ml}$, which is better than the lead compound $\mathbf{A}$ or $\mathbf{B}$. Most of compound $\mathbf{2}$ with substituent $\mathrm{R}$ on the benzene ring is more active than the unsubstituted compound $\mathbf{2 n}\left(\mathrm{IC}_{50}=\right.$ $13.67 \mu \mathrm{g} / \mathrm{ml}$ ). In terms of the substituent $\mathbf{R}$ at the 4-position of the benzene ring, some hydrophilic groups, such as carboxylate $\left(\mathbf{2} \mathbf{j}, \mathrm{IC}_{50}=9.34 \mu \mathrm{g} / \mathrm{ml}\right)$ and hydroxyl $\left(\mathbf{2 c}, \mathrm{IC}_{50}=\right.$ $11.25 \mu \mathrm{g} / \mathrm{ml}$ ) on the benzene ring, tend to enhance the activity significantly. Furthermore, some hydrophobic groups, such as carboxylate $\left(\mathbf{2} \mathbf{j}, \mathrm{IC}_{50}=9.34 \mu \mathrm{g} / \mathrm{ml}\right)$, halogen $\left(\mathbf{2 m}, \mathrm{IC}_{50}=13.39 \mu \mathrm{g} / \mathrm{ml}\right)$, nitro- $\left(\mathbf{2 s}, \mathrm{IC}_{50}=15.08 \mu \mathrm{g} / \mathrm{ml}\right)$, and acetylamino $\left(\mathbf{2 u}, \mathrm{IC}_{50}=13.14 \mu \mathrm{g} / \mathrm{ml}\right)$, also can enhance the activity. However, hydrophobic groups, such as the methoxy $\left(\mathbf{2 q}, \mathrm{IC}_{50}=27.58 \mu \mathrm{g} / \mathrm{ml}\right)$ and dimethylamine $(\mathbf{2 k}$, $\mathrm{IC}_{50}=34.31 \mu \mathrm{g} / \mathrm{ml}$ ), weaken the activity instead. The hydrophilic substituents have a more pronounced effect than the hydrophobic substituents on the inhibition activity.

The influence on the activities of substituent $\mathrm{R}$ at the 4position of the benzene ring is as follows: $\mathrm{COOCH} 3>$ $\mathrm{COOH}>\mathrm{OH}>\mathrm{NHCOCH}_{3}>\mathrm{F}>\mathrm{NO}_{2}>\mathrm{H}>\mathrm{NH}_{2}>\mathrm{OCH}_{3}$ $>\mathrm{N}\left(\mathrm{CH}_{3}\right)_{2}$. In general, most of compound 2 possesses better activity than compound $\mathbf{1}$. So we can draw the conclusion that the influence on the activities of substituent groups at 4and 5-position of the thiazole ring is as follows: 4- $\mathrm{CH}_{3}-5-$ $\mathrm{COCH}_{3}>4-\mathrm{CH}_{2} \mathrm{CO}_{2}$ Et. 


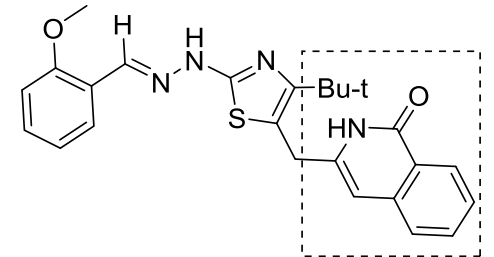

$A \mid C_{50}=17.38 \mathrm{ug} / \mathrm{ml}$<smiles>O=[N+]([O-])c1cc(/C=N/Nc2nc(Br)c(-n3cncn3)s2)c(O)c([N+](=O)[O-])c1</smiles>

B IC $_{50}=10.51 \mathrm{ug} / \mathrm{ml}$

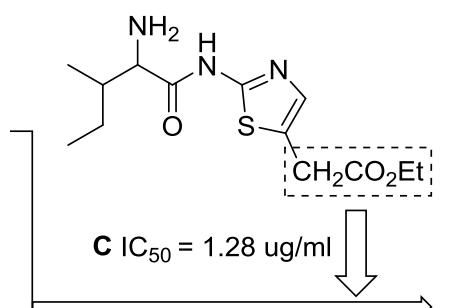

Structural modification

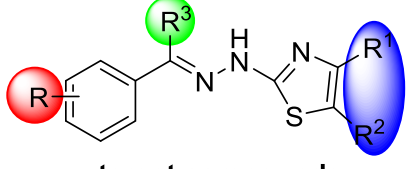

target compounds

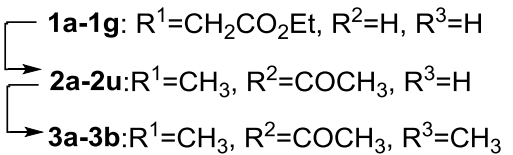

$2 \mathrm{~g} \mathrm{IC}_{50}=7.12 \mathrm{ug} / \mathrm{ml}$

$2 \mathrm{i} I \mathrm{C}_{50}=8.61 \mathrm{ug} / \mathrm{ml}$

2j IC I0 $_{50}=9.34 \mathrm{ug} / \mathrm{ml}$

Fig. 1 Design of target compounds

Scheme 1 Synthesis of target compounds

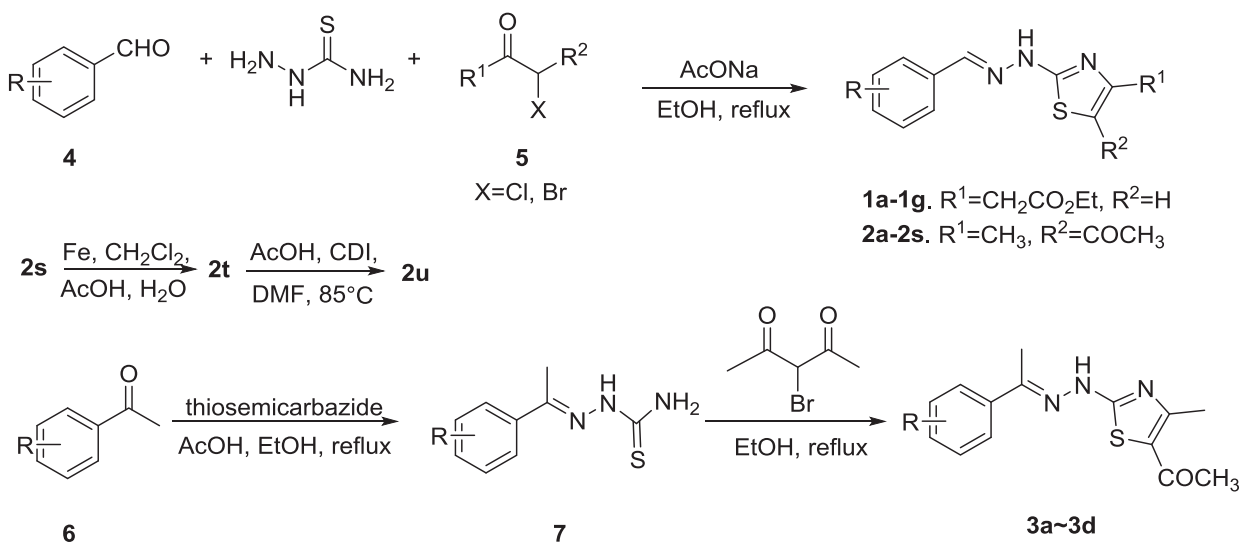

a: $\mathrm{R}=2-\mathrm{OH}, \mathbf{b}: \mathrm{R}=3-\mathrm{OH}, \mathbf{c}: \mathrm{R}=4-\mathrm{OH}, \mathbf{d}: \mathrm{R}=2,4-(\mathrm{OH})_{2}, \mathbf{e}: \mathrm{R}=2-\mathrm{OH}-3-\mathrm{OCH}_{3}, \mathbf{f}: \mathrm{R}=3-$ $\mathrm{OH}-4-\mathrm{OCH}_{3}, \mathbf{g}: \mathrm{R}=4-\mathrm{OH}-3-\mathrm{OCH}_{3}, \mathbf{h}: \mathrm{R}=3,4-(\mathrm{OH})_{2}, \mathbf{i}: \mathrm{R}=4-\mathrm{COOCH}_{3}, \mathbf{j}: \mathrm{R}=4-\mathrm{COOH}, \mathbf{k}$ : $\mathrm{R}=4-\mathrm{N}\left(\mathrm{CH}_{3}\right)_{2}, \mathbf{l}: \mathrm{R}=3-\mathrm{F}, \mathbf{m}: \mathrm{R}=4-\mathrm{F}, \mathbf{n}: \mathrm{R}=\mathrm{H}, \mathbf{o}: \mathrm{R}=3-\mathrm{Cl}, \mathbf{p}: \mathrm{R}=2,4-\mathrm{Cl}_{2}, \mathbf{q}: \mathrm{R}=4-\mathrm{OCH}_{3}$, r: $\mathrm{R}=3,4-\left(\mathrm{OCH}_{2} \mathrm{O}\right), \mathbf{s}: \mathrm{R}=4-\mathrm{NO}_{2}, \mathbf{t}: \mathrm{R}=4-\mathrm{NH}_{2}, \mathbf{u}: \mathrm{R}=4-\mathrm{NHAc}$

Table 1 Inhibitory activity of compound $\mathbf{1}$ against NA in vitro

\begin{tabular}{llll}
\hline Compound & $\mathrm{R}$ & Inhibition rate $(\%)$ & $\mathrm{IC}_{50}(\mu \mathrm{g} / \mathrm{ml})$ \\
\hline 1a & $2-\mathrm{OH}$ & 41.96 & $\mathrm{NA}^{\mathrm{a}}$ \\
1b & $3-\mathrm{OH}$ & 67.96 & $21.02 \pm 2.41$ \\
1c & $4-\mathrm{OH}$ & 73.22 & $17.92 \pm 1.60$ \\
1d & $2,4-(\mathrm{OH})_{2}$ & 55.90 & $31.83 \pm 1.07$ \\
1e & $2-\mathrm{OH}-3-\mathrm{OCH}_{3}$ & 47.54 & $\mathrm{NA}$ \\
1f & $3-\mathrm{OH}-4-\mathrm{OCH}_{3}$ & 19.47 & $\mathrm{NA}$ \\
$\mathbf{1 g}$ & $4-\mathrm{OH}-3-\mathrm{OCH}_{3}$ & 56.99 & $31.54 \pm 1.26$ \\
$\mathbf{C}^{\mathrm{b}}$ & - & -1.99 & $\mathrm{NA}$ \\
$\mathbf{C}^{\mathrm{c}}$ & - & - & 1.28 \\
\hline
\end{tabular}

${ }^{a}$ The inhibition rate is less than $50 \%$ at the the test concentration of $40 \mu \mathrm{g} / \mathrm{mL}$

${ }^{\mathrm{b}}$ The activity result in test experiment

${ }^{c}$ Activity values in the literature (Liu et al. 2011)
In order to make sure if the $\mathrm{CH}_{3}$ on $\mathrm{R}^{3}$ can affect the activity against NA, we designed and synthesized compound 3. As shown in Table 3, only compounds 3a and 3d with 2-OH and 2,4-di-OH on the benzene ring showed the potent inhibition activities against NA with $\mathrm{IC}_{50}$ values of 22.46 and $19.86 \mu \mathrm{g} / \mathrm{ml}$, respectively, which are much lower than those of compound 2 . As a result, substituent $\mathrm{CH}_{3}$ on $\mathrm{R}^{3}$ can weaken the inhibition activity. In summary, the SAR of the 2-thiazolylhydrazone derivatives is summarized in Fig. 2.

\section{Docking analysis}

In order to understand the interaction between the thiazolylhydrazone scaffold and the NA active site, the representative compounds $\mathbf{1 g}, \mathbf{2 g}$, and $\mathbf{3 c}$ were docked into the active sites of NA (H1N1, PDB entry: 3TI6), respectively, 
Table 2 Inhibitory activity of compound $\mathbf{2}$ against NA in vitro

\begin{tabular}{lllr}
\hline Compound & $\mathrm{R}$ & Inhibition rate $(\%)$ & $\mathrm{IC}_{50}(\mu \mathrm{g} / \mathrm{ml})$ \\
\hline $\mathbf{2 a}$ & $2-\mathrm{OH}$ & 77.62 & $16.19 \pm 2.75$ \\
$\mathbf{2 b}$ & $3-\mathrm{OH}$ & 87.93 & $11.83 \pm 1.23$ \\
$\mathbf{2 c}$ & $4-\mathrm{OH}$ & 85.77 & $11.25 \pm 0.23$ \\
$\mathbf{2 d}$ & $2,4-(\mathrm{OH})_{2}$ & 88.57 & $12.91 \pm 1.73$ \\
$\mathbf{2 e}$ & 2-OH-3-OCH & 89.39 & $12.66 \pm 0.60$ \\
$\mathbf{2 f}$ & $3-\mathrm{OH}-4-\mathrm{OCH}_{3}$ & 85.98 & $14.15 \pm 2.71$ \\
$\mathbf{2 g}$ & $4-\mathrm{OH}-3-\mathrm{OCH}_{3}$ & 93.33 & $7.12 \pm 0.80$ \\
$\mathbf{2 h}$ & $3,4-(\mathrm{OH})_{2}$ & 65.13 & $23.00 \pm 1.89$ \\
$\mathbf{2 i}$ & $4-\mathrm{COOCH}$ & 89.93 & $8.61 \pm 0.12$ \\
$\mathbf{2 j}$ & $4-\mathrm{COOH}$ & 91.16 & $9.34 \pm 0.46$ \\
$\mathbf{2 k}$ & $4-\mathrm{N}_{3}\left(\mathrm{CH}_{3}\right)_{2}$ & 54.51 & $34.31 \pm 3.24$ \\
$\mathbf{2 l}$ & $3-\mathrm{F}$ & 73.19 & $17.08 \pm 3.45$ \\
$\mathbf{2 m}$ & $4-\mathrm{F}$ & 85.29 & $13.39 \pm 1.28$ \\
$\mathbf{2 n}$ & $\mathrm{H}$ & 78.74 & $13.67 \pm 1.37$ \\
$\mathbf{2 o}$ & $3-\mathrm{Cl}_{2}$ & 86.38 & $12.44 \pm 1.06$ \\
$\mathbf{2 p}$ & 2,4-Cl & 64.52 & $22.14 \pm 3.81$ \\
$\mathbf{2 q}$ & $4-\mathrm{OCH}_{3}$ & 63.99 & $27.58 \pm 2.51$ \\
$\mathbf{2 r}$ & $3,4-\left(\mathrm{OCH}_{2} \mathrm{O}\right)$ & 71.68 & $21.05 \pm 2.03$ \\
$\mathbf{2 s}$ & $4-\mathrm{NO}_{2}$ & 86.79 & $15.08 \pm 0.19$ \\
$\mathbf{2 t}$ & $4-\mathrm{NH}_{2}$ & 84.94 & $14.90 \pm 1.31$ \\
$\mathbf{2 u}$ & $4-\mathrm{NHAc}^{2}$ & 80.99 & $13.14 \pm 1.18$ \\
\hline
\end{tabular}

Table 3 Inhibitory activity of compound $\mathbf{3}$ against NA in vitro

\begin{tabular}{llll}
\hline Compound & $\mathrm{R}$ & Inhibition rate $(\%, 40 \mu \mathrm{g} / \mathrm{ml})$ & $\mathrm{IC}_{50}(\mu \mathrm{g} / \mathrm{ml})$ \\
\hline 3a & $2-\mathrm{OH}$ & 67.36 & $22.46 \pm 3.23$ \\
3b & $3-\mathrm{OH}$ & 41.87 & $\mathrm{NA}^{\mathrm{a}}$ \\
3c & $4-\mathrm{OH}$ & 47.55 & $\mathrm{NA}$ \\
3d & $2,4-(\mathrm{OH})_{2}$ & 74.60 & $19.86 \pm 2.25$
\end{tabular}

${ }^{a}$ The inhibition rate is less than $50 \%$ at the the test concentration of $40 \mu \mathrm{g} / \mathrm{mL}$

using LeDock (http://www.lephar.com/) with default parameters, and the results were analyzed and visualized using PyMOL (http://pymol.sourceforge.net/) (Wang et al. 2016; Zhao et al. 2012). LigPlot+v1.4.5 was used to depict the 2D interaction diagram (Wallace et al. 1995).

According to the results in Fig. 3 (A1), it could be found that the structure orientation of compound $2 \mathrm{~g}$ and oseltamivir structure in the SA cavity are similar and they can fit well with the SA cavity. There are six hydrogen bonds formed between compound $\mathbf{2 g}$ and the amino acid residues of NA (Fig. 3 (A2)). The carbonyl group at the 5-position of the thiazole ring has a similar orientation with the acetamino group of Oseltamivir acid. Both of them form two hydrogen bonds with the amino acid residues of Arg 371 and Arg 292 , which is one of the reasons why the activity of acetyl substitution at the 5-position of the thiazole ring is better than others. Besides, similar with the carboxyl on oseltamivir acid interacting with a residue of $\operatorname{Arg} 152,3$ methoxy and 4-hydroxyl groups on the benzene ring have strong interactions with residues of Arg 152 and Trp178. In addition, the structural fragment $\mathrm{CH}=\mathrm{N}$ of Schiff base structure can also be interacting with the residues of Glu 119 and Tyr 406 by hydrogen bonds. In summary, the substituents on the phenyl ring, thiazole ring, and the schiff base structure are all playing essential roles in contributing to the higher inhibition activity against NA.

As shown in Fig. 4 (B1), the structure orientation of compound $1 \mathrm{~g}$ is also similar with oseltamivir in SA cavity. However, the $4-\mathrm{CH}_{2} \mathrm{CO}_{2} \mathrm{Et}$ on the thiazole ring extends beyond the 430-cavity. Besides, the hydrazone fragment is located on the corner of SA active cavity and 430 activity cavity. Neither $4-\mathrm{CH}_{2} \mathrm{CO}_{2} \mathrm{Et}$ on the thiazole ring nor the hydrazone fragment is deeply inserted into the two activity cavities. So they cannot interact strongly with the NA activity cavity. There are only three binding sites forming four hydrogen bonds (Fig. 4 (B2)). That is the reason why the activity of compound 1 with $4-\mathrm{CH}_{2} \mathrm{CO}_{2}$ Et substituent on the thiazole ring is lower than that of compound 2 with $4-\mathrm{CH}_{3}-5-\mathrm{COCH}_{3}$ on the thiazole ring. In Fig. $4(\mathrm{C} 1)$, the entire structure of compound $\mathbf{3 c}$ is hardly inside of the SA activity cavity and 430 activity cavity. Because of the effect of the methyl group on the hydrazone fragment, the thiazolylhydrazone skeleton cannot be inserted into the two activity cavities and they may be detached from the surface of NA activity cavity. There are two binding sites forming four hydrogen bonds (Fig. 4 (C2)), but the two sites are not able to immobilize compound $\mathbf{3 c}$ on the activity cavity. So compound $3 \mathbf{c}$ displays poor activity. The docking analysis result is consistent with the SAR analysis.

\section{Theoretical calculation}

Four electronic structure parameters of compound $\mathbf{2}$ were calculated, including the HOMO and LUMO orbital energy levels ( $\left.E_{\mathrm{HOMO}}, E_{\mathrm{LUMO}}\right)$, energy-level difference $(\Delta E)$, and oil-water partition coefficient $(\log P)$. The representative calculation results were shown in Table 4 (more calculation results can be found in Supporting information). From the calculation results, it can be found that $E_{\mathrm{HOMO}}$ and $\Delta E$ of the target compound 2 are not only close to each other, but also close to those of oseltamivir and oseltamivir acid. The energy-level difference $(\Delta E)$ of hydrophilic or electron-donating substituents is much closer to that of oseltamivir and oseltamivir acid, such as compounds $\mathbf{2 c}, \mathbf{2 g}$, and $2 \mathbf{2 r}$. Moreover, since the introduction of electron-donating substituents or molecular conjugate groups can contribute to improving the $\mathrm{E}_{\mathrm{HOMO}}$ and $\mathrm{E}_{\mathrm{LUMO}}$, it is significative to promote these energy levels of the target compounds closer to oseltamivir and oseltamivir acid to improve the biological activity. 
Fig. 2 Structure-activity relationship of 2thiazolylhydrazone derivatives

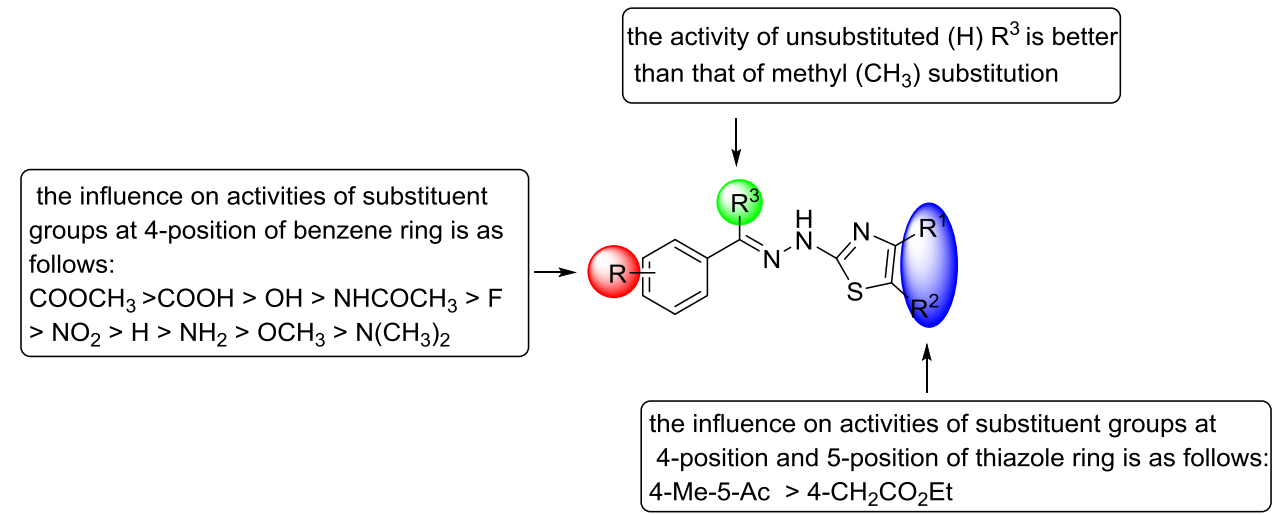

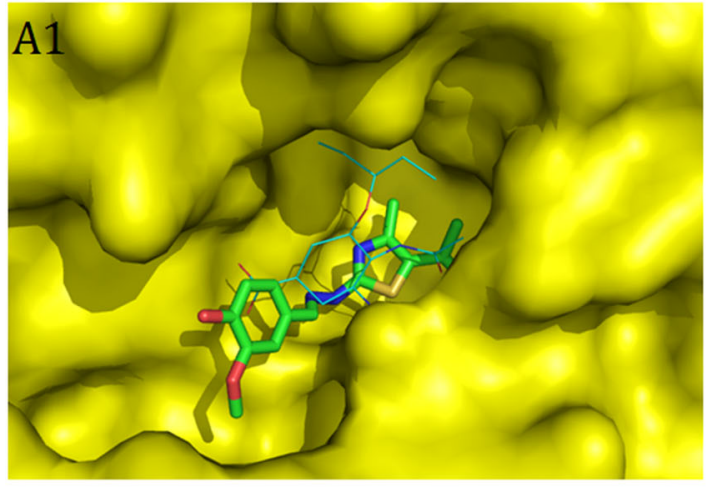

A2

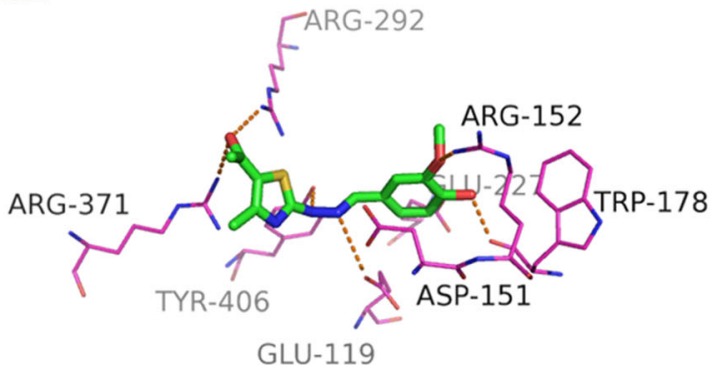

Fig. 3 Specific interactions of compound $\mathbf{2 g}$ and Oseltamivir acid binding to the active site of NA (H1N1, PDB: 3TI6). A1 The docking result of compound $\mathbf{2 g}$ and Oseltamivir acid binding to the active site

According to the frontier molecular orbital theory, HOMO and LUMO orbital energy levels are the most important factors that affected bioactivity (Nataraj et al. 2013). A study of the frontier orbital energy can provide some useful information for the active mechanism. DFT study is one of the most widely used computational methods due to its accuracy and less time consumption (Suvitha et al. 2014). So further calculation on frontier molecular orbital theory was conducted.

As shown in Fig. 5, the LUMO orbital of compound $\mathbf{2 g}$ is mainly distributed at the nitrogen atom of the thiazole ring and the carbon atom between the nitrogen atom and the sulfur atom, while the HOMO orbital is distributed at the

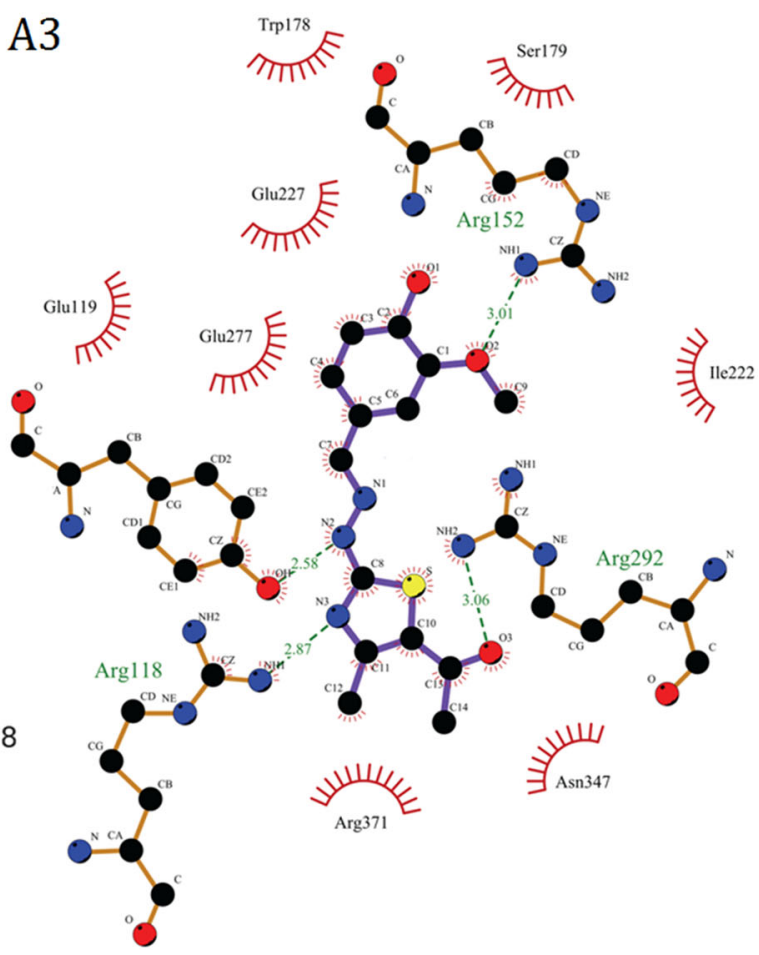

of NA (H1N1, PDB: 3TI6); A2 interaction between compound $\mathbf{2 g}$ with the corresponding amino acid residues of NA; $\mathbf{A 3}$ the 2D binding mode of compound $\mathbf{2 g}$

carbonyl group. The LUMO orbitals of oseltamivir or oseltamivir acid are mainly distributed at the carbonyl group of the carboxyl or ester group, while HOMO orbitals are distributed at the acetamide bond, especially at the carbonyl group of the acetamide bond. Figure 6 indicates that the HOMO orbital distribution of compound $\mathbf{2 g}$ and oseltamivir acid is almost identical on the structure of carbonyl. In addition, the electron transfer's direction from the HOMO to the LOMO orbit of $\mathbf{2} \mathbf{g}$ and oseltamivir acid is in accordance as well. According to the direction of electron transfer, it can be speculated that the electron-withdrawing groups on the benzene ring are more beneficial to electron transfer, which is similar with the effect of the carboxyl 
Fig. 4 Specific interactions of compound $1 \mathrm{~g}, \mathbf{3 c}$, and

Oseltamivir acid binding to the active site of NA (H1N1, PDB: 3TI6). B1 The docking result of compound $\mathbf{1 g}$ and Oseltamivir acid binding to the active site of NA (H1N1, PDB: 3TI6); B2 interaction between compound $1 \mathrm{~g}$ with the corresponding amino acid residues of NA; C1 the docking result of compound 3c and Oseltamivir acid binding to the active site of NA (H1N1, PDB: 3TI6); C2 interaction between compound $\mathbf{3 c}$ with the corresponding amino acid residues of NA
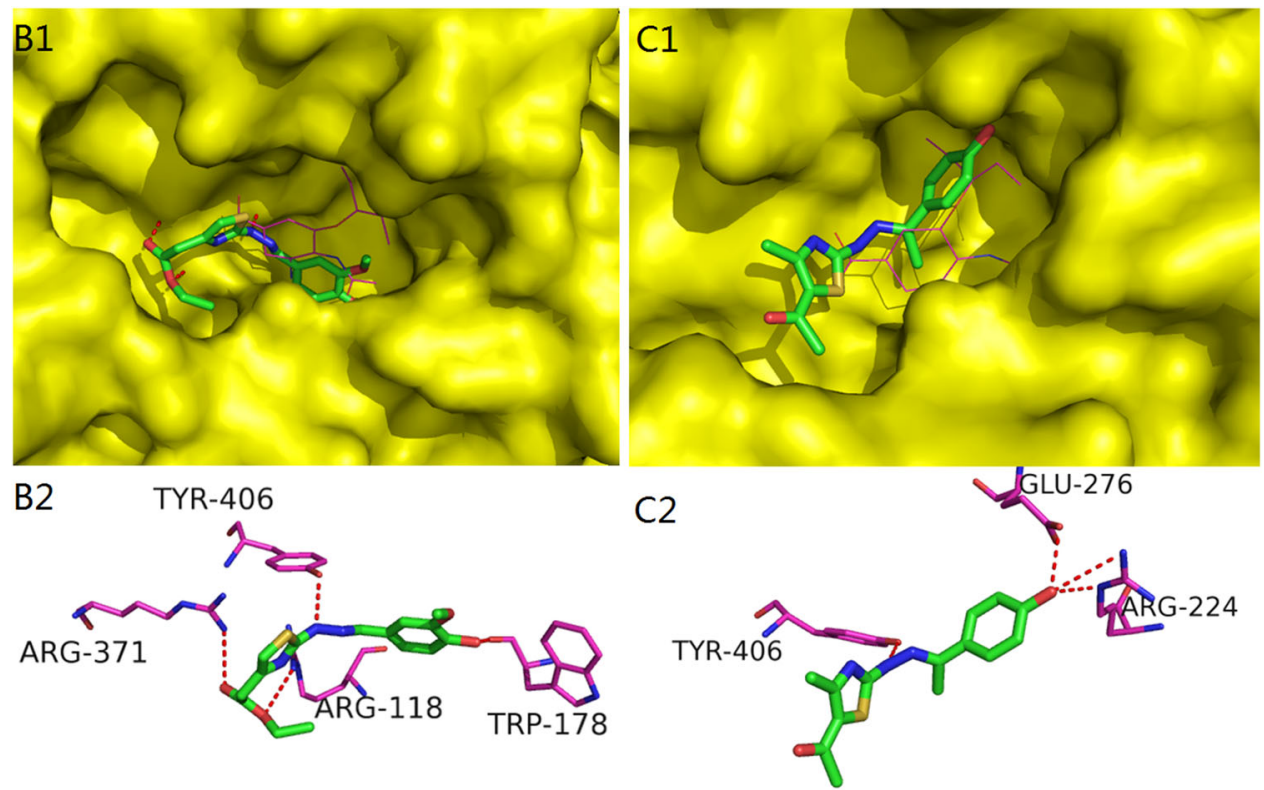

Table 4 Partial electronic structure parameters of compounds 2, 3, and Oseltamivir

\begin{tabular}{lcllll}
\hline Compound & $\mathrm{IC}_{50}(\mu \mathrm{g} / \mathrm{ml})$ & $E_{\text {HOMO }}($ a.u. $)$ & $E_{\text {LUMO }}($ a.u. $)$ & $\Delta E$ (a.u.) & $\log P$ \\
\hline $\mathbf{2 c}$ & $11.25 \pm 0.23$ & -0.24474 & -0.00987 & 0.23487 & 2.82 \\
$\mathbf{2 g}$ & $7.12 \pm 0.80$ & -0.24493 & -0.01052 & 0.23441 & 2.69 \\
$\mathbf{2 j}$ & $9.34 \pm 0.46$ & -0.25171 & -0.01712 & 0.23459 & 2.84 \\
$\mathbf{2 k}$ & $34.31 \pm 3.24$ & -0.23706 & -0.00409 & 0.23297 & 3.49 \\
$\mathbf{2 q}$ & $27.58 \pm 2.51$ & -0.24225 & -0.00899 & 0.23326 & 3.08 \\
$\mathbf{2 r}$ & $21.05 \pm 2.03$ & -0.24489 & -0.00990 & 0.23499 & 2.99 \\
$\mathbf{3 a}$ & $22.46 \pm 3.23$ & -0.24239 & -0.00491 & 0.23748 & 2.39 \\
$\mathbf{3 b}$ & $\mathrm{NA}^{\mathrm{a}}$ & -0.24447 & -0.01263 & 0.23184 & 2.39 \\
Oseltamivir & & -0.22892 & 0.01503 & 0.24395 & 0.19 \\
\hline
\end{tabular}

${ }^{a} \mathrm{NA}$ : the inhibition rate is less than $50 \%$ at the the test concentration of $40 \mu \mathrm{g} / \mathrm{mL}$ group on oseltamivir. To some extent, the frontier molecular orbital theory can explain the reason why the target compounds have anti-influenza activities.

Besides, the target compounds' oil-water partition coefficients $(\log P)$ are greater than those of oseltamivir and oseltamivir acid. Among compound 2, the $\log P$ of compounds $\mathbf{2 q}, \mathbf{2} \mathbf{j}$, and $\mathbf{2 k}$ is also greater than that of the most potent bioactivity compound $\mathbf{2 g}$. The calculation result of $\log P$ is consistent with the conclusion that the hydrophilic groups are more conducive to increased activity in the SAR analysis. So we can modify the lead compound by decreasing the $\log P$ value and enhancing the water solubility to improve anti-influenza activity.

\section{Conclusions}

Three series of compounds were designed, synthesized, and evaluated for their ability to inhibit NA of influenza H1N1 virus. Compound $\mathbf{2}$ has better activity than compound $\mathbf{1}$. The activities of compounds $\mathbf{2 g}$ and $\mathbf{2 i}$ with the $\mathrm{IC}_{50}$ values of 7.12 and $8.61 \mu \mathrm{g} / \mathrm{ml}$, respectively, are superior to the lead compound $\mathbf{B}$. The SAR analysis indicates that most of the substituents of $\mathrm{R}$ at the 4-position of the benzene ring can increase the inhibition activity, wherein the hydrophilic substituents have a more pronounced effect than the hydrophobic substituents on the inhibition activity. The specific influence on the activity of the substituent groups at 4-position $\left(\mathrm{R}^{1}\right)$ and 5position $\left(\mathrm{R}^{2}\right)$ on the thiazole ring is as follows: $4-\mathrm{CH}_{3}$ 5- $\mathrm{COCH}_{3}>4-\mathrm{CH}_{3} \mathrm{CO}_{2} \mathrm{Et}-5-\mathrm{H}$. The substituent $\mathrm{CH}_{3}$ on $\mathrm{R}^{3}$ can weaken the inhibition activity. Molecular docking indicates that the structure orientations of thiazolylhydrazone derivatives can fit well with the SA cavity. The thiazole ring and the structural fragment $\mathrm{CH}=\mathrm{N}$ of the thiazolylhydrazone skeleton can be interacting well with the amino acid residues by hydrogen bonds. DFT calculation suggests that the electron transfer's direction of compound $\mathbf{2} \mathbf{g}$ from the HOMO to the LOMO orbit is in accordance with that of oseltamivir acid. In addition, the 
Fig. 5 Frontier molecular orbital energy level and distribution of compound $2 \mathrm{~g}$, Oseltamivir acid, and Oseltamivir

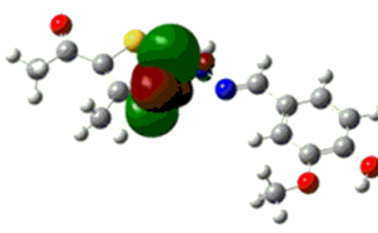

LUMO $2 \mathrm{~g}$

ELUMO $=-0.01052$

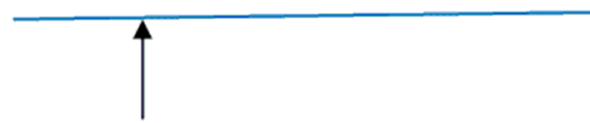

$\Delta \mathrm{E}=0.23441$

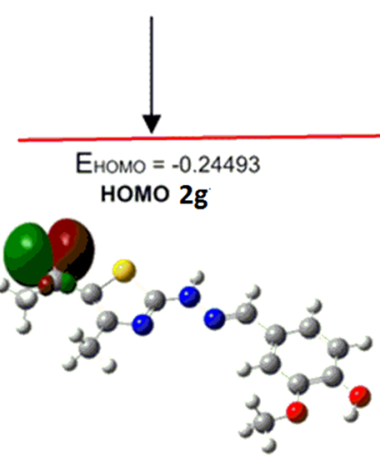

$\Delta \mathrm{E}=0.23992$

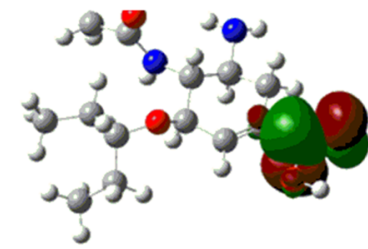

LUMO Oseltamivir acid ELUMo $=0.00943$

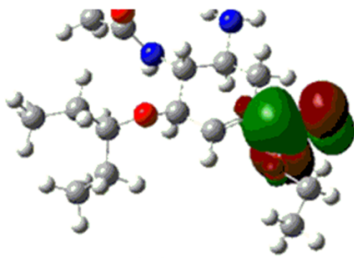

LUMO Oseltamivir ELUMo $=0.01503$

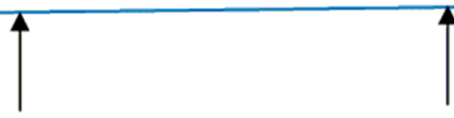

$\Delta \mathrm{E}=0.24395$
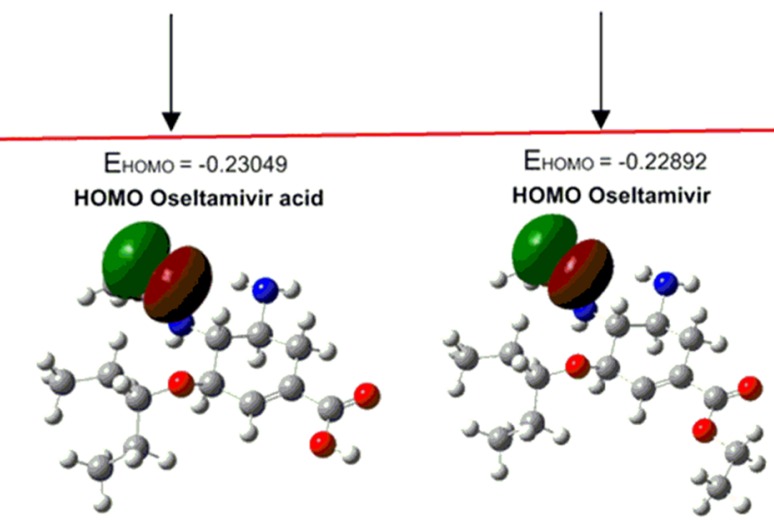

Fig. 6 Comparison of the frontier orbital distribution and the direction of electron transfer of compound $2 \mathrm{~g}$ and oseltamivir acid

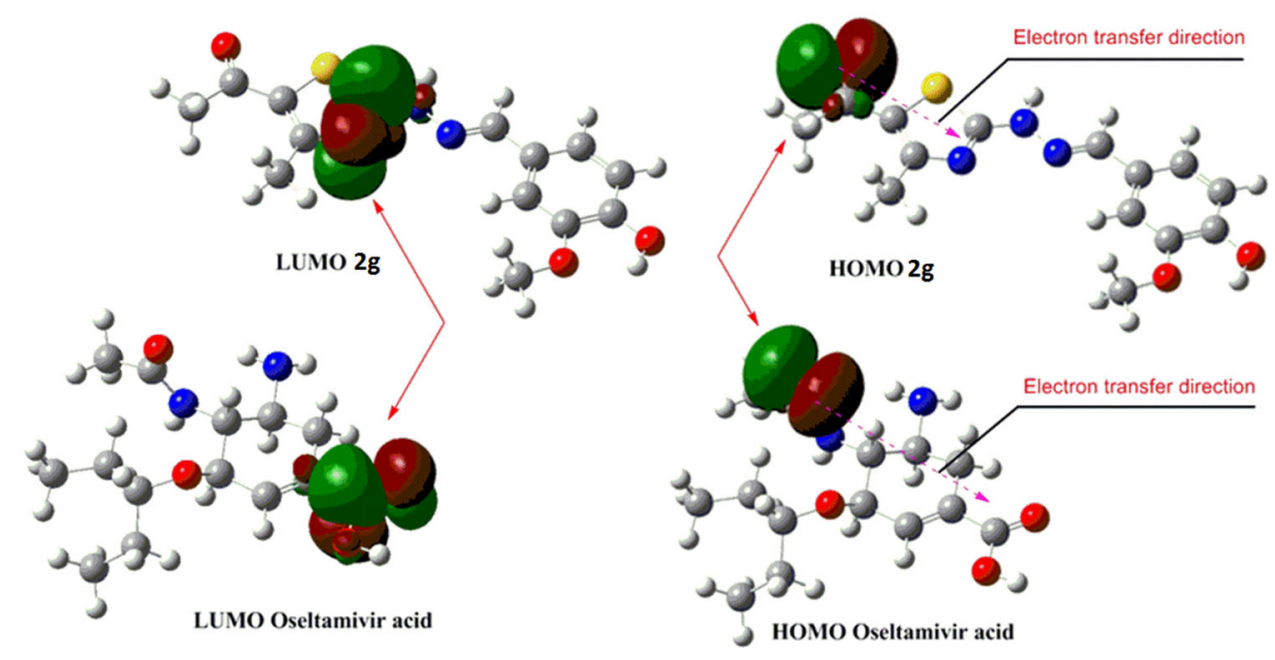

lower $\log P$ of thiazolylhydrazone derivatives also can contribute to improving activity. In summary, the thiazolylhydrazone skeleton could show potent NA inhibitory activity, which contributes to designing novel influenza NA inhibitors.

\section{Experiments}

\section{Chemistry}

The starting materials and solvents were commercially available and used without further purification. All reactions were monitored by thin-layer chromatography (TLC) on 25.4-6.2-mm silica gel plates (GF-254). Melting points were measured on an X-4 electrothermal digital melting point apparatus and uncorrected. Nuclear magnetic resonance (NMR) was recorded on a Varian INOVA-400 spectrometer apparatus using tetramethylsilane as an internal standard. The solvents for NMR were DMSO- $d_{6}$. Mass spectra data were obtained by an LCQ Advantage MAX spectrometer electrospray ionization-MS and an Agilent 1100 series LC-MS. The general procedure for the synthesis of compounds $\mathbf{1}, \mathbf{2}$, and $\mathbf{3}$ can be found in Supporting information. 
General procedure for the synthesis of compounds $1 \mathrm{a}-1 \mathrm{~g}$

A mixture of substituted benzaldehyde 4 ( $2 \mathrm{mmol})$, thiosemicarbazide ( $2 \mathrm{mmol})$, 4-chloro ethyl acetoacetate $(2.4 \mathrm{mmol})$, and sodium acetate $(0.1 \mathrm{mmol})$ in ethanol $(10 \mathrm{~mL})$ was refluxed for $6 \mathrm{~h}$. After the completion of the reaction confirmed by TLC, the reaction mixture was cooled at room temperature, and then poured into $10-\mathrm{ml}$ saturated $\mathrm{NaHCO}_{3}$ solution to adjust the $\mathrm{pH}$ to $8-10$. The precipitate was filtered and washed with brine, recrystallized from ethyl acetate/petroleum ether, or ethanol to afford the pure product $\mathbf{1 a - 1 g}$.

\section{General procedure for the synthesis of compounds $2 a-2 s$}

A mixture of substituted benzaldehyde 4 ( $2 \mathrm{mmol})$, thiosemicarbazide $(2 \mathrm{mmol})$, and 3-bromoacetylacetone $(2.4 \mathrm{mmol})$ and sodium acetate $(0.1 \mathrm{mmol})$ in ethanol $(10$ $\mathrm{mL}$ ) was refluxed for $6 \mathrm{~h}$. After completion of the reaction confirmed by TLC, the reaction mixture was cooled at room temperature, and then poured into $10-\mathrm{ml}$ saturated $\mathrm{NaHCO}_{3}$ solution to adjust the $\mathrm{pH}$ to $8-10$. The precipitate was filtered and washed with brine, and recrystallized from ethanol to afford the pure compounds $\mathbf{2 a - 2 s}$.

\section{Procedure for the synthesis of compound $2 t$}

A mixture of compound $2 \mathrm{~s}(2 \mathrm{mmol})$, iron powder $(15 \mathrm{mmol})$, dichloromethane $(20 \mathrm{ml})$, water $(20 \mathrm{ml})$, and glacial acetic acid $(20 \mathrm{ml})$ was vigorously stirred at room temperature for $15 \mathrm{~h}$. After the completion of the reaction confirmed by TLC, the precipitate was filtered and washed with dichloromethane $(50 \mathrm{ml})$. Then saturated sodium bicarbonate was dropped into the filtrate to adjust the $\mathrm{pH}$ to $7-8$. An organic layer was washed three times with water, dried with anhydrous sodium sulfate, and evaporated the solvent to afford the pure compound $\mathbf{2 t}$.

\section{Procedure for the synthesis of compound $2 u$}

$1,1^{\prime}$-Carbonyldiimidazole $(1.2 \mathrm{mmol})$ was added into the mixture solution DMF $(6 \mathrm{ml})$ and acetic acid $(1.2 \mathrm{mmol})$ in two portions and stirred for $30 \mathrm{~min}$ at room temperature. Then compound $2 \mathrm{t}(1 \mathrm{mmol})$ was added into the reaction solution. The mixture was stirred at $85^{\circ} \mathrm{C}$ for $5 \mathrm{~h}$ (confirmed by TLC), and cooled at room temperature. The reaction solution was poured into $10 \mathrm{ml}$ of water and stirred for $30 \mathrm{~min}$. The precipitate of the product was filtered and washed with water to afford the pure compound $\mathbf{2 u}$.

\section{General procedure for the synthesis of compounds $3 a-3 d$}

The appropriate thiosemicarbazide $(5.0 \mathrm{mmol})$, substituted acetophenone $6(5.5 \mathrm{mmol})$, was suspended in ethanol
$(20 \mathrm{ml})$, and two drops of acetic acid were added to the above solution. The reaction mixture was refluxed for $6-8 \mathrm{~h}$ and then cooled at room temperature. The resulting precipitate was filtered and washed with brine to obtain the corresponding thiosemicarbazone derivative 7.

A mixture of thiosemicarbazone derivative $7(2 \mathrm{mmol})$ and 3-bromoacetylacetone $(2.4 \mathrm{mmol})$ in ethanol $(10 \mathrm{~mL})$ was refluxed for $6 \mathrm{~h}$. The same workup as the synthesis of compounds 1a-1s was carried out to afford the products 3a-3d. The spectral data and figures of target compounds are shown in Supporting information.

\section{Neuraminidase inhibition assay}

All the target compounds were tested for their NA inhibitory activity in vitro using Oseltamivir as positive control. Influenza virus $\mathrm{A} / \mathrm{PR} / 8 / 34$, donated by Chinese Centers for Disease Control, was used as a source of NA in enzyme inhibition assays based on the method reported by Guanhua Du (Liu et al. 2005; Zhang et al. 2008). The NA was obtained by the method described by Laver et al. (1984). The compound 2'-(4-methylumbellifer-yl)- $\alpha$-D-acetyl neuraminic acid (MUNANA) was purchased from Sigma as the substrate of NA. Cleavage of this substrate by NA produces a fluorescent product, which can emit an emission wavelength of $450 \mathrm{~nm}$ with an excitation wavelength of $360 \mathrm{~nm}$ (Wetherall et al. 2003). The intensity of fluorescence can reflect the activity of NA sensitively (Mitrasinovic 2009).

The reaction mixture consisting of $10-\mu \mathrm{L}$ solution of target compounds and $30-\mu \mathrm{L}$ NA enzyme in $33 \mathrm{mmol} / \mathrm{L}$ MES buffer ( $\mathrm{pH} 3.5$ ) was added to a 96-well microtiter plate. Meanwhile, blank, enzyme, and a positive drug Oseltamivir were set. The reaction was started by the addition of a substrate containing $10 \mu \mathrm{L}$ of $4 \mathrm{mmol} / \mathrm{L} \mathrm{CaCl}_{2}$, $20 \mu \mathrm{L}$ of $20 \mu \mathrm{mol} / \mathrm{L}$ MUNANA, and $30 \mu \mathrm{L}$ of water to the plate. After incubation for $60 \mathrm{~min}$, the reaction was terminated by adding $150 \mu \mathrm{L}$ of $14 \mathrm{mmol} / \mathrm{L} \mathrm{NaOH}$ in $83 \%$ ethanol. The resulting fluorescence was quantified at an excitation wavelength of $360 \mathrm{~nm}$ and an emission wavelength of $450 \mathrm{~nm}$. The data are expressed as the mean of three independent experiments. The $\mathrm{IC}_{50}$ value was calculated by plotting the percent of inhibition of NA activity versus the inhibitor concentration.

\section{Docking study}

The crystal structure data of H1N1 neuraminidase-oseltamivir complex (PDB Code: 3TI6) were downloaded from RSCB Protein Data Bank. The docked compound 2g was energyminimized using the MM2 force fielld. Then LeDock was used to prepare the pdbqt files with default parameters (Wang et al. 2016; Zhao et al. 2012). The dimension of the binding box was set as $\left(X_{\min }=-37.4, X_{\max }=-19.8, Y_{\min }=7.0\right.$, 
$Y_{\max }=21.5, Z_{\min }=12.0$, and $Z_{\max }=30.2$ ). The results were analyzed and visualized by PyMOL. LigPlot+v1.4.5 was used to depict the 2D interaction diagrams (Wallace et al. 1995).

\section{DFT calculation}

The DFT calculations of the representative compounds were performed at the Becke-Lee-Parr hybrid exchange correlation three-parameter functional (B3LYP) level with standard 6-311G (d, p) basis set (Kohn et al. 1965; Becke 1993; Lee et al. 1998).

Vibration analysis showed that the optimized structure was in accordance with the minimum points on the potential energy surface. All of the convergent precisions were the system default values, and all the quantum chemical calculations in this study were performed using the Gaussian 09 program (Frisch et al., Gaussian 09, Revision A.1, Gaussian, Inc., Wallingford, CT, 2009). The calculated convergence accuracy is determined by the program default parameter.

Acknowledgements This work was financially supported by the Hunan Provincial Natural Science Foundation of China (No. 2019JJ40030). The institute of the Chinese Academy of Medical Sciences and Peking Union Medical College provided the biological activity assays.

\section{Compliance with ethical standards}

Conflict of interest The authors declare that they have no conflict of interest.

Publisher's note: Springer Nature remains neutral with regard to jurisdictional claims in published maps and institutional affiliations.

\section{References}

Baz M, Abed Y, Boivin G (2007) Characterization of drug-resistant recombinant influenza $\mathrm{A} / \mathrm{H} 1 \mathrm{~N} 1$ viruses selected in vitro with peramivir and zanamivir. Antiviral Res 74:159-162

Becke AD (1993) Density-functional thermochemistry. III. The role of exact exchange. J Chem Phy 98:5648-5652

Chavas LM, Kato R, Suzuki N, Itzstein MV, Mann MC, Thomson RJ, Dyason JC, Jennifer MB, Fusi P, Tringali C, Venerando B, Tettamanti G, Monti E, Wakatsuki S (2010) Complexity in influenza virus targeted drug design: interaction with human sialidases. J Med Chem 53:2998-3002

Colman PM, Varghese JN, Laver WG (2012) Structure of the catalytic and antigenic sites in influenza virus neuraminidase. Nature 303:41-44

Dawood FS, Iuliano AD, Reed C, Meltzer MI, Shay DK, Cheng PY, Bandaranayake D, Breiman RF, Brooks WA, Buchy P, Feikin DR, Fowler KB, Gordon A, Hien NT, Horby P, Huang QS, Katz MA, Krishnan A, Lal R, Montgomery JM, Mølbak K, Pebody R, Presanis AM, Razuri H, Steens A, Tinoco YO, Wallinga J, Yu H, Vong S, Bresee J (2012) Estimated global mortality associated with the first 12 months of 2009 pandemic influenza A H1N1 virus circulation: a modelling study. Lancet Infect Dis 12:687-695

Ellebedy AH, Webby RJ (2009) Influenza vaccines. Vaccine 27: D65-D68
Fang YL, Xiao MW, Hu AX, Ye J, Lian WW, Liu AL (2016) Design, synthesis, and evaluation of 3-((4-(t-Butyl)-2-(2-benzylidenehydrazinyl)thiazol-5-yl)methyl)quinolin- $2(1 \mathrm{H})$-ones as neuraminidase inhibitors. Chinese J Chem 34:403-411

Feng E, Ye DJ, Li J, Zhang DY, Wang JF, Zhao F, Hilgenfeld R, Zheng M, Jiang H, Liu H (2012) Recent advances in neuraminidase inhibitor development as anti-influenza drugs. ChemMedChem 7:1527-1536

Hatakeyama S, Sugaya N, Ito M, Yamazaki M, Ichikawa M, Kimura K, Kiso M, Shimizu H, Kawakami C, Koike K, Mitamura K, Kawaoka Y (2007) Emergence of influenza B viruses with reduced sensitivity to neuraminidase inhibitors. JAMA 297:1435-1442

Ison MG (2011) Antivirals and resistance: influenza virus. Curr Opin Virol 1:563-573

Kohn W, Sham LJ, Kohn W, Sham L (1965) Self-consistent equations including exchange and correlation effects. Phys Rev 140: A1133-A1138

Krammer F, Palese P (2015) Advances in the development of influenza virus vaccines. Nature Reviews Drug Discovery 14:167-182

Laver WG, Colman PM, Webster RG, Hinshaw VS, Air GM (1984) Influenza virus neuraminidase with hemagglutinin activity. Virology 137:314-323

Lee C, Yang W, Parr RG (1998) Development of the Colle-Salvetti correlation-energy formula into a functional of the electron density. Phys Rev B: Condens Matter 37:785-789

Liu AL, Cao HP, Du GH (2005) Drug screening for influenza neuraminidase inhibitors. Sci China C Life Sci 48:1-5

Liu Y, Zhang L, Gong JZ, Fang H, Liu AL, Du GH, Xu WF (2011) Design, synthesis, and biological activity of thiazole derivatives as novel influenza neuraminidase inhibitors. J Enzyme Inhib Med Chem 19:506-513

Lou Z, Sun Y, Rao Z (2014) Current progress in antiviral strategies. Trends Pharmacol Sci 35:86-102

Mitrasinovic PM (2009) On the structure-based design of novel inhibitors of H5N1 influenza A virus neuraminidase (NA). Biophys Chem 140:35-38

Nataraj A, Balachandran V, Karthick T (2013) Molecular structure, vibrational spectra, first hyperpolarizability and HOMO-LUMO analysis of p-acetylbenzonitrile using quantum chemical calculation. J Mol Struct 1038:134-144

Suvitha A, Periandy S, Boomadevi S, Govindarajan M (2014) Vibrational frequency analysis, FT-IR, FT-Raman, ab initio, HF and DFT studies, NBO, HOMO-LUMO and electronic structure calculations on pycolinaldeh yde oxime. Spectrochim Acta Part A 117:216-224

Takano R, Kiso M, Igarashi M, Le QM, Sekijima M, Ito K, Takada A, Kawaoka Y (2013) Molecular mechanisms underlying oseltamivir resistance mediated by an $\mathrm{I} 117 \mathrm{~V}$ substitution in the neuraminidase of subtype H5N1 avian influenza A viruses. J Infect Dis 207:89-97

The MIST (Management of Influenza in the Southern Hemisphere Trialists) Study Group (1998) Randomised trial of efficacy and safety of inhaled zanamivir in treatment of influenza A and B virus infections. Lancet 352:1877-1881

Wallace AC, Laskowski RA, Thornton JM (1995) LIGPLOT: a program to generate schematic diagrams of protein-ligand interactions. Protein Eng 8:127-134

Wang Z, Sun HY, Yao XY, Li D, Xu L, Li YY, Tian S, Hou TJ (2016) Comprehensive evaluation of ten docking programs on a diverse set of protein-ligand complexes: the prediction accuracy of sampling power and scoring power. Phys Chem Chem Phys 18:12964-12975

Wetherall NT, Trivedi T, Zeller J, Hodges SC, McKimm-Breschkin JL, Zambon M, Hayden FG (2003) Evaluation of neuraminidase enzyme assays using different substrates to measure susceptibility 
of influenza virus clinical isolates to neuraminidase inhibitors: report of the neuraminidase inhibitor susceptibility network. J Clin Microbiol 41:742-750

Yuan KY, Xiao MW, Tan Y, Ye J, Xie YL, Sun XX, Hu AX, Lian WW, Liu AL (2017) Design and one-pot synthesis of 2thiazolylhydrazone derivatives as influenza neuraminidase inhibitors. Mol Divers 21:1-12
Zhang J, Wang Q, Fang H, Xu WF, Liu AL, Du GH (2008) Design, synthesis, inhibitory activity, and SAR studies of hydrophobic paminosalicylic acid derivatives as neuraminidase inhibitors. Bioorg Med Chem 16:3839-3847

Zhao HT, Huang DZ, Caflisch A (2012) Discovery of tyrosine kinase inhibitors by docking into an inactive kinase conformation generated by molecular dynamics. ChemMedChem 7:1983-1990 